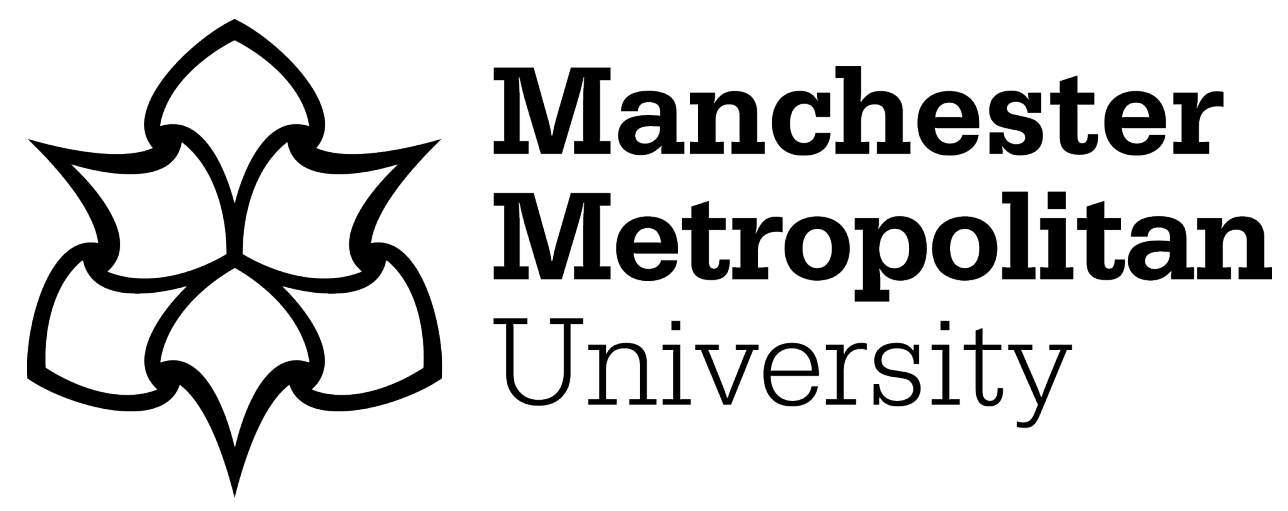

Joung, K, Rowley, JE ORCID logoORCID: https://orcid.org/0000-0003-34376914 and Sbaffi, L (2019) Medical and health sciences academics' behaviours and attitudes towards open access publishing in scholarly journals: a perspective from South Korea. Information Development, 35 (2). ISSN 0266-6669

Downloaded from: https://e-space.mmu.ac.uk/619310/

Version: Accepted Version

Publisher: SAGE Publications

DOI: https://doi.org/10.1177/0266666917736360

Please cite the published version 


\title{
Medical and health sciences academics' behaviours and attitudes towards open access publishing in scholarly journals: a perspective from South Korea
}

\begin{abstract}
This article seeks to extend the knowledge of the behaviour and attitudes towards open access publishing through a survey that focusses on the attitudes and behaviours of academic researchers in Korea working in medicine and healthcare. Issues covered include: use of and intentions regarding OAP, and perceptions regarding advantages and disadvantages of OAP, journal article publication services, peer review, and re-use. A significant proportion of the articles (mean 58\%) published by this group are published gold open access, consistent with the push in Korea towards international impact for their research. Researchers were more positive about the benefits of OAP than they were negative about its disadvantages. Analysis of responses on the basis of gender, and experience in publishing, showed some significant differences in attitudes to some statements.
\end{abstract}

Keywords: Open access publishing; scholarly communication; Korea; medicine; health sciences

\section{Introduction}

Open access (OA) to the findings of scholarly research is a growing international movement, intended to increase access to research outcomes by offering an alternative access route to subscription-based academic journals, which are typically accessible through the licences managed by university libraries. In addition, amongst the aspirations for open access is that it should lessen the strength of the commercial publishers, and reduce their capacity to generate further revenues through ever-increasing journal prices (Satyanarayana 2013). OA proponents point to the contradictory cycle of universities creating research outputs, in the form of journal articles, and then paying publishers to have access to these outputs. Others have discussed the relative merits of $\mathrm{OA}$ as an inevitable evolution of scholarly communication in a digital age and have recognised the potential for OA to de-stabilise scholarly communication (Jubb 2013; Lewis 2012) Certainly, we can look forward to a future that will depend on dynamic and interactive relationships between publishers, researchers, users, and information professionals (Bennett 2013). In particular, in less developed countries, and other countries such as Korea and India that are investing in developing research cultures and expertise, OA is expected to enhance access to scholarly resources, enhance research infrastructure, and facilitate an erosion of the divide between local and global journals (Mukherjee 2014).

Given the potential impact of open access publishing on scholarly communication, it is important to conduct research that monitors the development of open access through scholarly journals, and, explores the changing behaviours and attitudes of researchers. Indeed, academics, as researchers, authors, editors, and reviewers, are largely responsible for the intellectual content of scholarly communication in all of its forms, the success of the 'OA Project' depends heavily on them, and hence it is important to design a model of scholarly 
communication for the digital age that they will embrace, or even better to engage them in the co-creation of that model. As Mulligan and Mabe (2011a) suggest: 'changes to the scholarly information business model will only be successful if they continue to satisfy the underlying motivations and needs of researchers' (p. 290).

This article reports on a study that focusses on medicine and healthcare. Academics' attitudes towards open access publishing (OAP) in this discipline are especially important, due to the extent to which medicine and healthcare has been leading the way in OAP, both internationally, and more specifically in Korea (Zastrow 2016). There is evidence of considerable progress of the development of the processes associated with Korean medical journals, such as the use of e-submission systems, DOIs and open access Creative Commons Licence (Jeong and Huh 2016). In addition, with the increase in government investment in Research and Development in Science, Technology and Medicine, there is strong evidence of internationalisation of Korea's research outputs, supported by an open access policy and encouragement to publish in English. In 2015, half of Korea's STM research outputs were published in international journals indexed in Web of Science (Huh 2015).

This research aims to contribute to knowledge regarding behaviours and attitudes towards open access publishing amongst medical and health care academics in Korea. More specifically, the objectives of this research are to:

1. Profile medical and healthcare researchers' OA behaviour, in terms of:

a. recent publication activities

b. future intentions

2. Profile medical and healthcare researchers' attitudes towards OA, in terms of:

a. the advantages and disadvantages of OA

b. the relative importance of services associated with paid OA publication

c. preferences regarding peer review

d. the dissemination and re-use of their research

3. Investigate the impact of various demographic variables, including gender and publishing experience on behaviours and attitudes towards OA publishing.

Next, further detail is provided on research, scholarly communication and open access initiatives in Korea. This is followed by a literature review on academics' behaviours and attitudes towards OA, and on differences on the basis of discipline, gender and length of publishing experience. Then, the details of the survey of the behaviours and views of researchers in medicine and other health-based disciplines are outlined and evaluated. Next, findings are reported and discussed. Finally, conclusions and recommendations for future research and practice and policy are offered.

\section{Study Context}

South Korea is currently spending more than $4 \%$ of its Gross Domestic Product (GDP) on Research and Development; this is more than any other country in the world and double that of China and the European Union. Furthermore, South Korea has more than doubled its academic publication output since 2005, and in terms of number of articles published, medical 
and health sciences is the largest discipline (Zastrow 2016). Accordingly, this study focusses on medical and health sciences researchers in universities in Korea.

Open access in Korea includes open access repositories, managed by universities and other research bodies, toll access or gold open access journals, and 'dual ccess'. In relation to OAP, Korea has gold open access journals, where the content is free to access on the journal website or through open access repositories immediately on publication (Joung and Rowley 2017). However, the western models of green open access and hybrid open access, do not apply in Korea. In the western model, green OA is where either a subscription or OA journal allows its articles to be placed and made available in OA repositories. For subscription journals, the version made available is a pre-publication version. Hybrid OA is where a subscription (toll access) journal allows authors to choose whether their article is published OA, leading to a situation in which some articles are free to access (gold OA) and others are toll access; typically toll access journals have an embargo period after which they become free to access. In Korea, there are no green OA with embargo periods or hybrid OA journals. Instead, there are both open access (requiring no APC) and toll access journals (involving payment of an APC). Articles in both of these categories are ultimately available for free access via open access repositories and under toll/subscription access via commercial database providers, referred to as 'dual access' (Joung and Rowley 2017). There, is however, a possibility that green OA with embargo periods may be introduced in the future. In addition, those Korean authors publishing in international journals may have experienced this model.

\section{Literature Review}

A number of prior studies have examined the behaviours and attitudes of researchers regarding open access. An early survey undertaken by Key Perspectives Ltd, suggested that researchers, in general, had limited interest in OA, on account of a mix of lack of awareness and understanding, general disinterest, inertia, and a range of practical considerations (Swan 2006). The Study of Open Access Publishing (SOAP) project, conducted by a consortium of publishers, funding agencies and libraries, a cross-disciplinary worldwide survey identified funding and perceived quality as the main barriers to publishing in open access journals (Dallmeier-Tiessen et al. 2011). In addition, an important large-scale study of scholarly communication, sponsored by the Sloan Foundation and led by the University of Tennessee, touched on attitudes to open access and the role of peer review and suggested that researchers are confused and suspicious about open access (Nicholas et al. 2014). More recently, Rowley et al. (2017) reported on findings from an international and inter-disciplinary survey on open access journal publishing, reporting on: the use of and intentions regarding OAP, perceptions regarding advantages and disadvantages of OAP, journal article publication services, peer review, and re-use. They found progress with engagement with OAP, and highlighted the importance of rigorous peer review and rapid publication, and reported on concerns about reuse. Another recent study is reported by Tenopir et al. (2017). Based on a survey of academic at four US universities, they present insights into authors opinions and behaviours in regard of gold open access, with s specific focus on article processing charges (APC's). Both Tenopir et al. (2017) and Rowley et al. (2017), found, in common with Coonin and Younce (2009), evidence of some disciplinary differences in behaviours and attitudes regarding OAP, thus confirming the need for further studies to complement the many earlier studies that investigate specific disciplinary groups (e.g. Scroter et al. 2005; Warlick and Vaughan 2007; Fowler 2011). 
Disciplinary differences may derive from both disciplinary cultures and and/or the emphasis on OAP in specific disciplines. For example, the open access movement has its foundation in STM subjects; Dallmeier-Tiessen at al. (2011) found that STM accounts for $66 \%$ of pure and hybrid open access journals, and contributes $77 \%$ of articles. Tenopir et al. (2017) point to the effect of different funding regimes between STEM and arts and humanities on attitudes and behaviours, including familiarity with and confidence in OAP. For example, humanities scholars have been found to have a low awareness of repositories and make significantly less use of e-publications and open access services (Cullen and Chawner 2011; Heath et al. 2008) and penetration of open access has been much slower in the social sciences (Coonin and Younce 2009, 2010). In a recent study focussing on arts, humanities and social science disciplines, Rodriguez (2014) found that, although self-reported knowledge of OA was growing, publishing activity remained relatively limited. More generally, the culture of a discipline and its norms (or traditions) impact strongly on researchers' communication practices, including their relative reliance on journals, books and conference proceedings (Coonin and Younce 2009; Fry et al. 2009; Harley et al. 2010) and there is evidence that discipline culture influences the adoption and adaptations of digital scholarship (Kling and McKim 1999, 2000).

A number of discipline-based studies have been conducted and these offer an assortment of insights into the factors that influence the adoption of OAP. Amongst these studies are some on medicine. For example, in an early study of the OA perceptions of authors published in British Medical Journal, Schroter et al. (2005) found that authors were willing to consider publishing in open access journals (OAJs), but the quality and reputation of the journal, including impact factor, was a key consideration; charging policy was less important. Complementing these insights, Warlick and Vaughan (2007)'s interviews with biomedical faculty members who were early OA adopters at two major US research universities, suggested that incentives to publish in OAJs included audience accessibility and the potential for broad exposure; disincentives included cost, and lack of regard for OAJs. On the other hand, there is some evidence that in non-English speaking countries there is considerable concern amongst academics regarding lack of research grants or other means to pay for open access publication, and the potentially detrimental effect this could have on researchers in, for example, Spain and India (Hernandez-Borges et al. 2006; Singh, 2015).

Studies in other disciplines offer a range of insights into the factors that might affect engagement with OAP. Key amongst these factors is peer review. Coonin and Younce (2009), in a survey-based study of publishing in open access journals in the social sciences and humanities, concluded that peer review and peer acceptance are at the heart of scholarly and research endeavours. Two other studies, in education and business, respectively (Coonin and Younce 2010; Coonin 2011), confirm the importance of peer review in publication choice, irrespective of the business model used for publishing. Nicholas et al. (2015) argue the case for the continuing and growing importance of peer review, suggesting that 'the implicit trust that comes with peer review is very effective for reducing the complexity of today's disintermediated, overly abundant scholarly information environment because it enables scholars to come to decisions without first considering every possible eventuality' (p. 15). Other merits of traditional peer review are its contribution to improvement in the quality of the article, and that the publishers (with the aid of their editors) organise it, hence peer review is 
pivotal to the success of OAP. Yet, Nicholas et al. (2015) also suggests that academics are concerned about the peer review status of OA publications. On the other hand, PLOS ONE, has demonstrated the potential for an OA journal that publishes speedily, undertakes peer reviewing, and has a good impact factor (Curry 2013; Nicholas et al. 2015).

Other studies have identified additional factors that academics expect in OA journals. Solomon and Bjork (2012) found that quality/impact, and speed of review/publication, were the most important factors, after 'fit with the scope' determining journal choice for submission. Similarly, Mulligan and Mabe (2011a, b), in an analysis of Elsevier's author feedback programme, found that refereeing quality and refereeing speed were the most important factors influencing journal choice. Other important factors that influence the adoption of OAP include: speed of publication (Fowler 2011); impact and journal reputation (Russell and Kent 2010); and, impact factor, journal profile and reputation and quality and speed of the reviewing process (Bird 2010).

In addition to disciplinary differences, Jamali et al. (2014) suggested differences between research from less developed countries, such as India and China, and those in the US and the $\mathrm{UK}$; they indicated that researchers from less developed countries are more dependent on external factors that are related to authority, brand and reputation, including authors' names, affiliations, country, and journal names. Accordingly, these features of open access systems may be more important to researchers in countries whose scholarly communication system is less developed. Furthermore, with the exception of India and Nigeria (e.g. Mukherjee 2014; Oluwasemilore 2013; Sahu and Ayra 2013) there has been very limited research into open access initiatives, policies and challenges in countries other than the UK and the US.

\section{Summary and Contribution}

There has been considerable investment by key policy stakeholders including governments, research funders and publishers towards building an open access model of scholarly communication. Academics and other researchers are key to the success of this venture, but there have only been a limited number of prior studies that have investigated academics' attitudes towards the various aspects of open access publishing. Some of these studies are big international surveys, and some are based in a specific discipline or journal community. Amongst these there are some studies in the medicine and health sciences area, but given the centrality of this discipline to the open access field, more research would be beneficial. In addition, there have been few studies in non-western economies, and certainly none in South Korea. Hence, this article contributes to understanding of medicine and health science academics attitudes towards OAP, in the specific context of South Korea.

\section{Methodology}

\section{Process}

An online questionnaire-based survey of academic researchers in medicine and health sciences in South Korea was chosen as the research method. The use of a survey approach facilitated the gathering of data across scattered locations with Korea. The survey questionnaire was 
created in both English and Korean, to permit respondents to use their language of choice. The questionnaire was based on the 2014 Taylor and Francis Open Access Survey. This meant that the questions were tried and tested. The questionnaire asked academics about their behaviour and attitudes in respect of open access publishing, including: recent publication activities and future intentions, perceived advantages and disadvantages of OAP, the importance of services related to OAP, peer review preferences, and the re-use of their research and published outputs. The survey used Likert style (5-point) questions designed to gather information on attitudes, and closed questions to gather data on publishing activity and open access publishing intentions. Closed questions were also used to collect demographic data on discipline, age, gender, employer, professional status, and number of years since first publication (i.e. length of publishing career).

\section{Participants}

In order to identify academics with experience in publishing in medical and healthcare research journals, authors e-mail addresses were sourced from KoreaMed. KoreaMed is a service of the Korean Association of Medical Journal Editors (KAMJE) that provides access to articles published in Korean medical, dental, nursing, nutrition and veterinary journals (https://koreamed.org/SearchBasic.php). Author details and e-mail addresses were extracted from the most recent issues of the 215 KoreaMed journals in June 2016. An initial set of 2,597 email addresses was reduced by the removal of duplicates and of addresses outside of Korea. The questionnaire survey was sent via email to 1,936 corresponding authors in early 2017. 199 questionnaires were completed, a response rate of $10 \%$. All submitted questionnaires were checked for authenticity and reliability; 11 questionnaires were incomplete, such that a final set of 188 questionnaires was analysed.

Table 1 shows the demographic profile of the sample.

\section{Data analysis}

Data were entered into IBM SPSS Statistics 23. The dataset was initially inspected for errors and out-of-range values in each variable. Confidence intervals were calculated for each question to ensure that the response sample provided adequate representation of the population. The maximum confidence interval (at a 95\% confidence level) for any one question is 1.16 , suggesting that for all questions we can be $95 \%$ that the true percentage of the entire population who would give that response would fall within $+/-1.16 \%$ of the percentage of the sample giving that response.

Descriptive statistics and means and standard deviations were calculated for each of the statements. Not all respondents answered all of the questions; hence, total numbers included vary between questions. Subsequently, independent samples t-tests were carried out to compare mean scores on gender and one-way between-groups ANOVA with post-hoc tests were performed to compare mean scores according to the years of experience of the respondent. 
Table 1. Demographics.

\begin{tabular}{|c|c|c|c|}
\hline \multicolumn{2}{|c|}{ Demographics } & Frequency & $\%$ \\
\hline \multirow[t]{5}{*}{ Discipline } & Medicine & 131 & 84.0 \\
\hline & Dentistry & 6 & 3.8 \\
\hline & Nursing & 11 & 7.1 \\
\hline & Pharmacy & 2 & 1.3 \\
\hline & Allied Health & 6 & 3.8 \\
\hline \multirow[t]{4}{*}{ Professional status } & Professor & 79 & 48.2 \\
\hline & Associate Professor & 27 & 16.5 \\
\hline & Assistant Professor & 37 & 22.6 \\
\hline & Other & 21 & 12.8 \\
\hline \multirow{5}{*}{$\begin{array}{l}\text { Years since } 1^{\text {st }} \\
\text { publication }\end{array}$} & $<5$ years & 26 & 16.0 \\
\hline & $5-9$ years & 29 & 17.8 \\
\hline & $10-14$ years & 49 & 30.1 \\
\hline & $15-19$ years & 28 & 17.2 \\
\hline & $20+$ years & 31 & 19.0 \\
\hline \multirow[t]{3}{*}{ Employer } & Academic & 108 & 66.3 \\
\hline & Health / Medical & 52 & 31.9 \\
\hline & Other & 3 & 1.8 \\
\hline \multirow[t]{4}{*}{ Age } & $30-39$ & 30 & 18.3 \\
\hline & $40-49$ & 94 & 57.3 \\
\hline & $50-59$ & 35 & 21.3 \\
\hline & $60-69$ & 4 & 2.4 \\
\hline \multirow[t]{2}{*}{ Gender } & Female & 54 & 32.9 \\
\hline & Male & 110 & 67.1 \\
\hline
\end{tabular}

\section{Findings and discussion}

\section{Academics' OA Behaviour}

Tables $2 \mathrm{a}$ and $2 \mathrm{~b}$ summarise the responses to questions on academics' current OA behaviour, and their intentions for the future. Overall, academics report publishing an average of 4.48 articles in the twelve months prior to the survey, with more than half of these being published as gold open access (Table 2a). In addition, there is a higher level of publication in subscription journals, for foreign journals, but, in contrast a higher level of publication in domestic journals in the case of publication in gold open access. This level of access is consistent with Joung (2011) which showed that the ratio of open access journals was higher in medicine than in other fields. Tenopir et al. (2017) also comment on the difference in attitudes between sciences, medicine and engineering and arts and humanities in terms of their more positive attitudes towards and acceptance of OAP. With regard to academics' future intentions regarding engagement with gold and green OA, there was a high level of uncertainty as to whether they expected to extend their engagement with green open access, either by choice or by mandate. Many will choose to publish more open access articles in the future $-37.5 \%$ gold OA and $28.6 \%$ green OA. On the other hand, a significant proportion, just over one fifth, declared that they will neither choose to or be mandated to publish more articles as either green or open access. Given the relatively high level of engagement with gold and green OA, these 
researchers may feel that they have reached a steady state, or it may be an indication of the prevailing ambivalence towards OAP (Tenopir et al. 2017).

\section{Advantages and disadvantages of $\mathrm{OAP}$}

Table 2c, questions 3-1 to 3-6, and questions 4-1 to 4-3, respectively, offers insights into views on the advantages and disadvantages of OA. Responses to the first three questions in Table 3 report on perceptions relating to circulation, visibility, and readership. Consistent with Rowley et al. (2017) and Tenopir et al. (2017), respondents were convinced that OA offers wider circulation (in the sense that more people can access their articles), and higher visibility (within the scholarly community) than publication in a subscription journal. Of these two, academics are most likely to be concerned about visibility within the scholarly community (Cullen and Chawner 2011; Warlick and Vaughan 2007). Respondents also thought that open access journals have faster publication times than subscription journals, but they are more ambivalent as to whether OA journals are cited more heavily than subscription journals or drive innovation in research.

Questions 4-1 to 4-3 ask about potential disadvantages of OA. The first two statements relate to the quality and production standards of OAJs, respectively. Overall, there was a great deal of ambivalence regarding these issues, with both having means close to 3.0; this contrasts with earlier studies that suggest that OAJs are perceived to be of lower quality than traditional journals, due to concerns regarding peer review (Coonin and Younce 2009; Coonin 2011; Dallmeier-Tiessen et al. 2011; Schroter et al. 2005). This increase in confidence in OAP is also weakly evident in the relatively negative responses to the statement: 'There are no fundamental benefits to OA publication' and there is some indication from Tenopir et al. (2017) that this is part of the growing confidence in OAP in STEM disciplines.

\section{OAP services}

Table 2c, questions 5-1 to 5-9, offers insights into the priorities of medical and healthcare academics as regards OAP services. The most important consideration is rapid peer review, supported by rapid publication. These issues have variously been mentioned by other authors (e.g. Curry 2013; Solomon and Bjork 2012; Mulligan and Mabe 2011a, b). On the other hand, only Rowley et al. (2017) offer a relative ranking for these two factors; their ranking contrasts with the findings in this study, with rigour being valued above rapidity. Again in contrast to Rowley et al. (2017), which reported a number of other relatively high ranking services, the only other services that were regarded as important were provision of usage and citation figures at the article level and, pre-peer review services, such as language checking and paper formatting. Academics, in their roles as reviewers and editors, make a considerable contribution to the delivery of this service. For example, the speed of peer review is largely in the hands of reviewers and editors (Rowley et al. 2017). Other statements relate to: guidance on increasing the visibility of a paper, automatic deposit of a paper, and, provision of alt metrics, all of which it seems that whilst being appreciated, were not regarded as pivotal. This may be because they are relatively new, such that respondents do not have sufficient experience to be able to judge their usefulness. For example, it is interesting that provision of alt-metrics, a relatively new service, is rated considerably less important than usage and citation figures. 


\section{Peer Review Styles}

As indicated previously, peer review is regard as pivotal to trust in scholarly communication (Nicholas et al. 2015), and has been identified as an important consideration in medical researchers' decisions regarding publication in OA journals (Schroter et al. 2005). Hence, the study sought to identify which approaches to peer review were most favoured by respondents (Table 2c, questions 6-1 to 6-4). Strongest support was evident for 'a rigorous assessment of the merit and novelty of my articles with constructive comments for its improvement, even if this takes a long time'. This contradicts responses to 5-1 and 5-2, where rapidity is seen to be preferred to rigour, although some support was also lent to 'accelerated peer review with fewer rounds of revision'. It seems that medical academics in Korea find it difficult to choose between speed and rigour of review. They are however, less in favour of reviewing based on the technical soundness of articles with no judgement on novelty or contribution, such as is being operated by some megajournals (Bjork and Catani 2016). In addition, consistent with Rowley et al. (2017), post-publication peer review did not attract much support.

\section{Dissemination and re-use}

Finally, Table 2c, questions 7-1 to 7-7, summarises attitudes on dissemination and re-use of research. All statements in this table had the proviso: 'without my prior knowledge or permission, provided I receive credit as the original author'. Respondents are relatively comfortable about the re-use of their work for non-commercial gain. On the other hand, they were very unhappy about others adapting their work or using their work for commercial gain. However, in contrast, a relatively positive response was offered on the issue of re-use for noncommercial gain, and, in contrast to the findings from Rowley et al. (2017), they were quite positive about the use of their work in text or data mining, and its translation. In this context, it is useful to note that of the 233 journals in KoreaMed, 183 journals had adopted the CC-BY$\mathrm{NC}$ license. The issue of re-use has received very little attention beyond the publisher's controls over deposit of versions of articles in repositories (Bjork 2004) and in Rowley et al. (2017), so the insights from this study are important.

\section{Impact of Gender and Experience}

Tables 3 and 4 show the statements on which there are some differences on the basis of gender and years of experience, respectively. Table 3, gender, includes only six of the statements in the questionnaire; for all other statements there is no significant difference. Even for those statements where there is a significant difference, the effect size is medium. In respect of the first two statements, relating to readership and citation, women seem a little more positive about open access journals than men. In addition, they prioritise rapid publication more than men but respond less favourably to suggestions that their work be re-used or translated.

Table 4 reveals some differences in attitudes on the basis of 'years since first publication', a proxy for publishing experience. Four statements show a significant difference on the basis of publishing experience. The first relates to the potential for OAP to offer higher visibility that publication in subscription journal. The mean for this statement increases stepwise with years of publishing experience. The other three statements all concern the importance of various features of peer review. Rapid publication was significantly more important for the $15+$ years group than for the 10-14 years group. For rigorous peer review there were significant 
differences between the 0-9 years group and the 10-14 years group, as well as between the 0-9 years groups and the $15+$ years group. In relation to the provision of altmetrics, opinions differed between the 0-9 years group and the 10-14 years group, and between the 10-14 years group and the $15+$ years group. The differences in the value placed on higher visibility may be associated with the fact that senior researchers seeking board membership of a scholarly journal may view visibility and rigorous peer review as important in this process.

\section{Conclusion and recommendations}

\section{Summary}

This article draws on data from a survey conducted in Korea amongst academics in medicine and health sciences. As such, it contributes to understanding gathered through other earlier studies that have focussed on specific discipline or journal communities, and, more specifically offers some insights into attitudes towards OAP amongst medicine and health science academics, in respect of medical and healthcare academics' OA behaviour, views on OA, and differences on the basis of gender and publishing experience.

A significant proportion of the articles (mean 58\%) published by this group are published gold open access, consistent with the push in Korea towards international impact for their research. On the other hand, there is some ambivalence regarding whether researchers will be increasing this level of publication. Researchers viewed the potential for wider circulation, followed by higher visibility than publication in a subscription journal, as the key advantages of OAP. In respect of publishing services, rapid review and rapid publication were valued more than rigour in peer review. Researchers preferred traditional peer review processes that focussed on the merit and novelty of their contribution. Concerning re-use, researchers were happy for their articles to be used for non-commercial gain, in text and data mining, and for them to be translated, but they were unhappy about adaptations, and the use of their work for commercial gain. Finally, there was some evidence that gender and publishing experience influenced views on OAP. Women seem a little more positive about OAP than men, and prioritise rapid publication more than men, but respond less favourably than men to suggestions that their work be re-used or translated. On experience, there were differences between experience groups regarding the visibility of OAJ's, the importance of rapid publication and rigorous review, and the provision of altmetrics.

\section{Recommendations}

Overall, this study suggests that medical and health sciences academics in Korea are relatively positive about open access. This growing positivity amongst STEM disciplines has also been identified by in a study by Tenopir et al. (2017). It would seem that a combination of funding support, expectations and growing familiarity with OAP, at least in respect of well-regarded journals operating the conventional double blind reviewing based on evaluation of novelty and contribution, is encouraging this group of academics to participate in OAP publishing. For South Korea, their investment in research and development will be re-paid by high visibility of research outputs, both within Korea and more internationally. However, there is potential that there will be an ever-widening gap between those disciplines that are more generously supported by research funding and those that are not. 
This study has been conducted amongst researchers in a specific discipline within one country, and whilst the response rate was within expected norms, the sample size is relatively small. Hence, there is scope for further research regarding attitudes to open access in various countries, and disciplines. In addition, it would be valuable if further research were to explore:

1. The dynamic between rigour and rapidity in reviewing. There are some ambiguities in this study and others as to whether researchers prioritise rigour or speed of review. Further elucidation in this area might also inform understanding of preferences for review models.

2. Views on re-use. Whilst various CCL's are in operation, it is not clear whether academics are aware of the implications of such licences, and there is some variation in the types of re-use that have been reported as acceptable to authors. It would be useful to profile in more detail author's views in this area, with specific emphasis on disciplinary and cultural influencers.

3. The effect of demographic variables on behaviours and attitudes to OAP. Previous studies have explored disciplinary differences, but little research has been conducted on other demographic variables, such as gender and experience of publishing in general, and OAP publishing, more specifically. It would be important not only to identify any differences, but to seek insights into the origins of such differences.

\section{References}

Bennett R (2013) The changing role of the publisher in the scholarly communications process. In: D. Shorley and M. Jubb (Eds.) The Future of Scholarly Communication. London: Facet.

Bird C (2010) Continued adventures in open access: 2009 perspective. Learning Publishing 23(2): 107-116.

Bjork B-C (2004) Open access to scientific publications - an analysis of the barriers to change. Information Research 9(2).

Bjork B-C and Catani P (2016) Peer review in megajournals compared with traditional scholarly journals: Does it make a difference? Learned Publishing 29(1): 9-12.

Coonin B (2011) Open access publishing in business research: the authors' perspective. Journal of Business and Finance Librarianship 16(3).

Coonin B and Younce L (2009) Publishing in open access journals in the social sciences and humanities: who's doing it and why? ACRL Fourteenth National Conference, March 12-15, Seattle, Washington.

Coonin B and Younce LM (2010) Publishing in open access educational journals: the authors' perspectives. Behavioral and Social Sciences Librarian 29(2): 118-132. 
Cullen R and Chawner B (2011) Institutional repositories, open access, and scholarly communication: a study of conflicting paradigms. Journal of Academic Librarianship 37(60): 460-470.

Curry S (2013) Political, cultural and technological dimensions of open access: an exploration. In: N. Vincent and C. Wickham (Eds.) Debating Open Access. London: British Academy, pp. 55-67.

Dallmeier-Tiessen S, Darby R, Goerner B, Hyppoelae J, Igo-Kemenes P, Kahn D, Lambert S, Lengenfelder A, Leonard C, Mele S, Nowicka M, Polydoratou P, Ross D, Ruiz-Perez S, Schimmer R, Swaisland M and van der Stelt W (2011) Highlights form the SOAP Project Survey: What scientists think about open access publishing. arXiv: 1101.5260. Available online at: http://arxiv.org/ftp/arxiv/papers/1101/1101.5260.pdf

Fowler KK (2011) Mathematicians' Views on Current Publishing Issues: A Survey of Researchers. University of Minnesota Digital Conservancy. Available online at: http://conservancy.umn.edu/bitstream/handle/11299/109309/Fowler_mathscholcomm_survey article.pdf?sequence $=1$

Harley D, Accord SK, Earl-Novell S, Shannon L and King CJ (2010) Assessing the Future Landscape of Scholarly Communication: An Exploration of Faculty Values and Needs in Seven Disciplines. Center for Studies in Higher Education, UC Berkeley, Berkeley, CA. Available online at: https://escholarship.org/uc/item/15x7385g

Fry J, Oppenheim C, Creaser C, Greenwood H, Spezi V and White S (2009). PEER Behavioural Research Baseline Report. Available online at: http://www.stmassoc.org/2010_01_20_Final_revision_behavioural_baseline_report.pdf

Heath M, Jubb M and Robey D (2008) E-publication and open access in the arts and humanities in the UK. Ariadne 54. Available online at: http://www.ariadne.ac.uk/issue54/heath-et-al

Hernández-Borges, AA, Cabrera-Rodríguez, R, Montesdeoca-Melián, A, Martínez-Pineda, B, Torres-Álvarez de Arcaya, ML and Jiménez-Sosa, A (2006). Awareness and attitude of Spanish medical authors to open access publishing and the "author pays" model. Journal of the Medical Library Association 94(4): 449-e218.

Huh S (2015) How STM journals from Korea are becoming more internationalized. Available online at: http://www.editage.com/insights/how-stm-journals-from-korea-are-becomingmore-internationalized

Jamali HR, Nicholas D, Watkinson A, Herman E, Tenopir C, Levine K, Allard S, Christian L, Volentine R, Boehmg R and Nichols F (2014) How scholars implement trust in their reading, citing and publishing activities. Library and Information Science Research 36(3-4): 192-202.

Jeong HH and Huh S (2016) Status of digital standards in Korean medical journals in 2016. Science Editing 3(2): 100-104.

Joung KH (2011) Characterisitcs of open access journals in Korea: Focussed on KCI journals. Journal of the Korean Biblia Society for Library and Information Science 223(3): 373-391. 
Joung KH and Rowley JE (2017) Scholarly publishing and open access: perspectives from Korea. Learned Publishing, Accepted.

Jubb M (2013) Introduction. In: D. Shorley and M. Jubb (Eds.) The Future of Scholarly Communication. London: Facet.

Kling R and McKim G (1999) Scholarly communication and the continuum of electronic publishing. Journal of the American Society for Information Science 50(10): 890-906.

Kling R and McKim G (2000) Not just a matter of time differences and the shaping of electronic media in supporting scientific communication: Scholarly communication and the continuum of electronic publishing. Journal of the American Society for Information Science and Technology 51(14): 1306-1320.

Lewis DW (2012) The inevitability of open access. College and Research Libraries 73(5): 493506.

Mukherjee B (2014) Green and gold open access in India. Learned Publishing 21(1): 21-32.

Mulligan A and Mabe M (2011a). The effect of the internet on research motivations, behaviour and attitudes. Journal of Documentation 67(2): 290-311.

Mulligan A and Mabe M (2011b) What journal authors want: ten years of results from Elsevier's Author Feedback Programme. New Review of Information Networking 16(1): 71-89.

Nicholas D, Watkinson A, Volentine R, Allard S, Levine K, Tenopir C and Herman, E (2014) Trust and authority in scholarly communications in the light of the digital transition: setting the scene for a major study. Learned Publishing 27(2): 121-134.

Nicholas D, Watkinson A, Jamali HR, Herman E, Tenopir C, Volentine R, Allard S and Levine K (2015) Peer review: still king in the digital age. Learned Publishing 28(1): 15-21.

Oluwasemilore IA (2013) Issues and challenges in the development of open access publishing and communications in Nigeria. Retrieved from: http://digitalscholarship.unlv.edu/aaas_pacific_conf/2013/june17/1/

Rodriguez JE (2014) Awareness and attitudes about open access publishing: a glance at generational differences. Journal of Academic Librarianship 40: 604-610.

Rowley J, Johnson F, Sbaffi L, Frass W and Devine E (2017) Academic' behaviors and attitudes towards open access publishing in scholarly journals. Journal of the Association for Information Science and Technology 68(5): 1201-1211.

Russell J and Kent TK (2010) Paved with gold: an institutional case study on supporting open access publishing. Serials 23(7): 97-102.

Sahu SK and Ayra SK (2013) Open access practice in India. Library Hi Tech News 30(4): 612.

Satyanarayana K (2013) Journal publishing: the changing landscape. Indian Journal of Medical Research 138(1): 4-7. 
Schroter S, Tite L and Smith R (2005) Perceptions on open access publishing: interviews with journal authors. British Medical Journal 330(7494): 656-759.

Singh, HP (2015) Knowledge and attitude of health researchers from India towards 'Paying to Publish' and open access journals. Indian Pediatrics 52: 252-253. http://indianpediatrics.net/mar2015/mar-252-253.htm

Solomon DJ and Bjork B-C (2012) Publication fees in open access publishing: sources of funding and factors influencing choice of journal. Journal of the American Society for Information Science and Technology 63(1): 98-107.

Swan A (2006) The culture of open access: researchers' views and responses. In: N. Jacobs (Ed.), Open access: Key strategic, technical and economic aspects (pp.65-72). Oxford, UK: Chandos.

Tenopir C, Dalton ED, Christian L, Jones MK, McCabe M, Smith M and Fish A (2017) Imagining a Gold Open Access Future: Attitudes, Behaviors, and Funding Scenarios among Authors of Academic Scholarship. College and Research Libraries. Earlycite.

Warlick SE and Vaughan KTL (2007) Factors influencing publication choice: why faculty choose open access. Biomedical Digital Libraries 4(1).

Zastrow M (2016) Why South Korea is the world's biggest investor in research. Nature 534: 20-23. 
Table 2. Descriptive statistics.

(a) Publishing activity

\begin{tabular}{|c|c|c|c|c|c|}
\hline $\begin{array}{c}\text { In the last 12 months, how many } \\
\text { articles have you published? }\end{array}$ & N & Min & Max & Mean & sd \\
\hline $\begin{array}{c}\text { Where a subscription is required to } \\
\text { access the article? (Total number of } \\
\text { articles published in foreign and } \\
\text { domestic journals) }\end{array}$ & 187 & 0 & 25 & 4.47 & 4.71 \\
\hline In foreign journals from among these? & 182 & 0 & 20 & 3.31 & 3.89 \\
\hline In domestic journals from among these? & 179 & 0 & 12 & 1.59 & 1.96 \\
\hline $\begin{array}{c}\text { As Gold Open Access, where the article } \\
\text { is freely available to everyone? (Total } \\
\text { number of articles published in foreign } \\
\text { and domestic journals) }\end{array}$ & 188 & 0 & 14 & 2.61 & 2.79 \\
\hline $\begin{array}{c}\text { In foreign journals from among these? } \\
\text { In domestic journals from among these? }\end{array}$ & 176 & 0 & 12 & 1.64 & 2.20 \\
\hline
\end{tabular}

(b) Open access publishing expectations

\begin{tabular}{|c|c|c|c|c|c|c|}
\hline $\begin{array}{c}\text { What are your future intentions } \\
\text { regarding OA and your own } \\
\text { research? }\end{array}$ & Yes & $\begin{array}{c}\text { Yes } \\
\mathbf{( \% )}\end{array}$ & Unsure & $\begin{array}{c}\text { Unsure } \\
\mathbf{( \% )}\end{array}$ & No & $\begin{array}{c}\text { No } \\
\mathbf{( \% )}\end{array}$ \\
\hline $\begin{array}{c}\text { I will choose to publish more articles as } \\
\text { Gold Open Access }\end{array}$ & 66 & 37.5 & 70 & 39.9 & 40 & 22.7 \\
\hline $\begin{array}{c}\text { I will be required to publish more } \\
\text { articles as Gold Open Access }\end{array}$ & 59 & 33.7 & 85 & 48.6 & 31 & 17.7 \\
\hline $\begin{array}{c}\text { I will choose to publish more articles as } \\
\text { Green Open Access }\end{array}$ & 50 & 28.6 & 88 & 50.3 & 37 & 21.1 \\
\hline $\begin{array}{c}\text { I will be mandated to publish more } \\
\text { articles as Green Open Access }\end{array}$ & 28 & 16.0 & 104 & 59.4 & 43 & 24.6 \\
\hline
\end{tabular}


(c) Views on Open access

\begin{tabular}{|c|c|c|c|c|c|}
\hline Section & Code & Statement & Mean & $s d$ & Scale \\
\hline \multirow{6}{*}{ 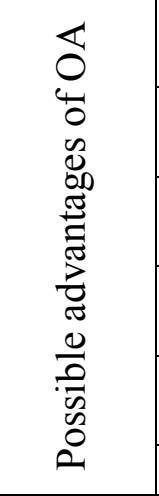 } & $3-1$ & $\begin{array}{l}\text { Open access offers wider circulation than publication } \\
\text { in a subscription journal }\end{array}$ & 4.06 & 0.88 & \multirow{9}{*}{$\begin{array}{c}1=\text { strongly } \\
\text { disagree } \\
5=\text { strongly } \\
\text { agree }\end{array}$} \\
\hline & $3-2$ & $\begin{array}{l}\text { Open access offers higher visibility than publication } \\
\text { in a subscription journal }\end{array}$ & 3.80 & 1.00 & \\
\hline & $3-3$ & $\begin{array}{l}\text { Open access journals have a larger readership of } \\
\text { researchers than subscription journals }\end{array}$ & 3.47 & 1.01 & \\
\hline & $3-4$ & $\begin{array}{l}\text { Open access journals are cited more heavily than } \\
\text { subscription journals }\end{array}$ & 3.16 & 1.05 & \\
\hline & $3-5$ & $\begin{array}{l}\text { Open access journals have faster publication times } \\
\text { than subscription journals }\end{array}$ & 3.56 & 0.95 & \\
\hline & $3-6$ & Open access drives innovation in research & 3.19 & 0.97 & \\
\hline \multirow{3}{*}{ 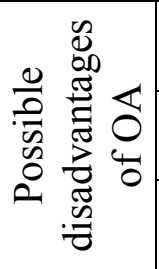 } & $4-1$ & $\begin{array}{c}\text { Open access journals are lower quality than } \\
\text { subscription journals }\end{array}$ & 3.05 & 0.94 & \\
\hline & $4-2$ & $\begin{array}{c}\text { Open access journals have lower production } \\
\text { standards than subscription journals }\end{array}$ & 2.79 & 0.94 & \\
\hline & $4-3$ & $\begin{array}{l}\text { There are no fundamental benefits to open access } \\
\text { publication }\end{array}$ & 2.57 & 0.83 & \\
\hline \multirow{9}{*}{ 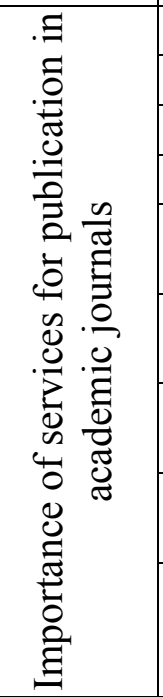 } & $5-1$ & Rapid peer review & 4.12 & 0.77 & \multirow{9}{*}{$\begin{array}{c}1=\text { not } \\
\text { important } \\
5=\text { very } \\
\text { important }\end{array}$} \\
\hline & $5-2$ & Rigorous peer review & 3.62 & 0.80 & \\
\hline & $5-3$ & Rapid publication of my paper & 3.86 & 0.80 & \\
\hline & $5-4$ & Promotion of my paper post-publication & 3.34 & 0.85 & \\
\hline & $5-5$ & $\begin{array}{c}\text { Detailed guidance on how I can increase the visibility } \\
\text { of my paper }\end{array}$ & 3.26 & 0.85 & \\
\hline & $5-6$ & $\begin{array}{l}\text { Automated deposit of my paper (Author Accepted } \\
\text { Version) into a repository of my choice }\end{array}$ & 3.18 & 0.85 & \\
\hline & $5-7$ & $\begin{array}{c}\text { Provision of usage and citation figures at the article } \\
\text { level }\end{array}$ & 3.78 & 0.84 & \\
\hline & $5-8$ & $\begin{array}{l}\text { Provision of alt-metrics (such as Altmetric or } \\
\text { ImpactStory) }\end{array}$ & 3.33 & 0.80 & \\
\hline & $5-9$ & $\begin{array}{c}\text { Pre-peer review services such as language polishing, } \\
\text { matching my paper to a journal, and / or formatting } \\
\text { my paper to journal style }\end{array}$ & 3.48 & 0.86 & \\
\hline \multirow{4}{*}{ 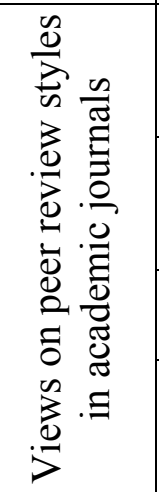 } & $6-1$ & $\begin{array}{l}\text { A rigorous assessment of the merit and novelty of my } \\
\text { article with constructive comments for its } \\
\text { improvement, even if this takes a long time }\end{array}$ & 3.88 & 0.71 & \multirow{4}{*}{$\begin{array}{c}1=\text { never } \\
5=\text { always }\end{array}$} \\
\hline & $6-2$ & $\begin{array}{c}\text { Accelerated peer review that reviews the technical } \\
\text { soundness of my research without any judgement on } \\
\text { its novelty or interest }\end{array}$ & 3.34 & 0.74 & \\
\hline & $6-3$ & $\begin{array}{c}\text { Accelerated peer review with fewer rounds of } \\
\text { revision }\end{array}$ & 3.40 & 0.80 & \\
\hline & $6-4$ & $\begin{array}{l}\text { Post-publication peer review after a basic formal } \\
\text { check by invited reviewers that my work is } \\
\text { scientifically sound }\end{array}$ & 2.64 & 0.82 & \\
\hline \multirow{2}{*}{ 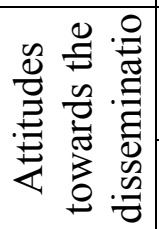 } & $7-1$ & $\begin{array}{l}\text { It is acceptable for my work to be reused provided } \\
\text { the new author applies the same reuse conditions as I } \\
\text { applied when I published the work }\end{array}$ & 3.45 & 0.88 & \multirow{2}{*}{$\begin{array}{c}1=\text { strongly } \\
\text { disagree } \\
5=\text { strongly } \\
\text { agree }\end{array}$} \\
\hline & $7-2$ & $\begin{array}{l}\text { It is acceptable for my work to be reused for non- } \\
\text { commercial gain }\end{array}$ & 3.92 & 0.73 & \\
\hline
\end{tabular}




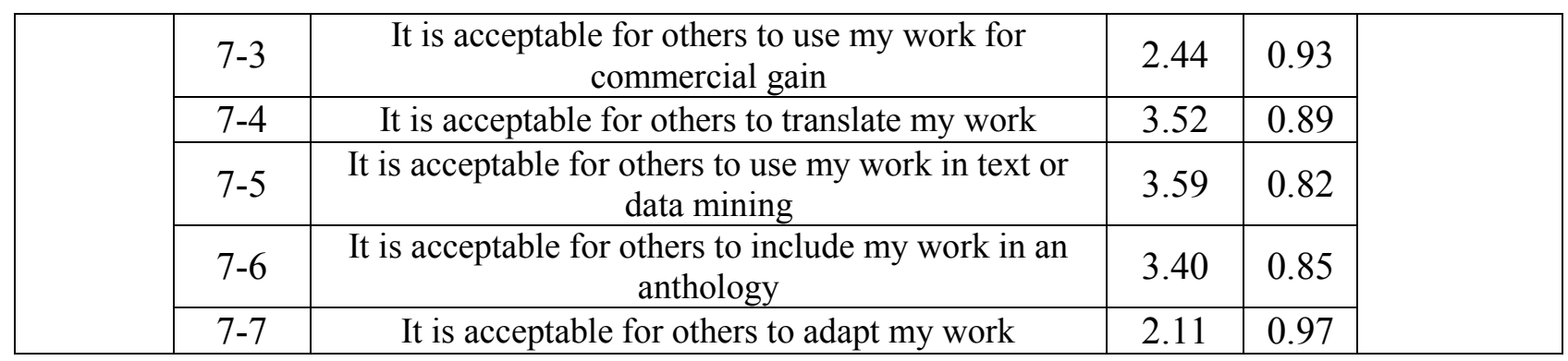

Table 3. Results of the independent sample t-tests conducted on gender.

\begin{tabular}{|c|c|c|c|c|c|c|c|c|}
\hline \multirow{2}{*}{ Code } & \multirow{2}{*}{ Statement } & \multicolumn{2}{|c|}{ Females } & \multicolumn{2}{|c|}{ Males } & \multicolumn{3}{|c|}{$\begin{array}{c}\text { t-test } \\
\text { Females-Males } \\
\end{array}$} \\
\hline & & Mean & sd & Mean & sd & $t$ & $p$ & $\begin{array}{l}\text { Effect } \\
\text { size }\end{array}$ \\
\hline $3-3$ & $\begin{array}{l}\text { Open access journals have a larger } \\
\text { readership of researchers than } \\
\text { subscription journals }\end{array}$ & 3.69 & 1.03 & 3.33 & 0.97 & 2.140 & 0.034 & 0.03 \\
\hline $3-4$ & $\begin{array}{l}\text { Open access journals are cited more } \\
\text { heavily than subscription journals }\end{array}$ & 3.48 & 0.99 & 3.04 & 1.07 & 2.562 & 0.011 & 0.04 \\
\hline $4-1$ & $\begin{array}{l}\text { Open access journals are lower } \\
\text { quality than subscription journals }\end{array}$ & 2.85 & 0.86 & 3.18 & 0.96 & -2.105 & 0.037 & 0.03 \\
\hline $5-3$ & Rapid publication of my paper & 4.09 & 0.78 & 3.75 & 0.78 & 2.649 & 0.009 & 0.04 \\
\hline $7-2$ & $\begin{array}{l}\text { It is acceptable for my work to be } \\
\text { reused for non-commercial gain }\end{array}$ & 3.74 & 0.76 & 4.02 & 0.69 & -2.342 & 0.020 & 0.03 \\
\hline $7-4$ & $\begin{array}{l}\text { It is acceptable for others to translate } \\
\text { my work }\end{array}$ & 3.22 & 0.95 & 3.67 & 0.84 & -3.105 & 0.002 & 0.06 \\
\hline
\end{tabular}

Table 4. Results of the one-way ANOVA tests conducted on the years since first publication.

\begin{tabular}{|c|c|c|c|c|c|c|c|c|c|c|}
\hline \multirow[b]{2}{*}{ Code } & \multirow[b]{2}{*}{ Statement } & \multicolumn{2}{|c|}{ 0-9 years } & \multicolumn{2}{|c|}{$10-14$ years } & \multicolumn{2}{|c|}{$15+$ years } & \multicolumn{3}{|c|}{ ANOVA } \\
\hline & & Mean & $\mathrm{sd}$ & Mean & sd & Mean & $\mathrm{sd}$ & $F$ & $p$ & $\begin{array}{c}\text { Effect } \\
\text { size }\end{array}$ \\
\hline $3-2$ & $\begin{array}{l}\text { Open access offers higher } \\
\text { visibility than publication in } \\
\text { a subscription journal }\end{array}$ & $3.56^{1}$ & 1.04 & 3.77 & 0.91 & 4.02 & 0.96 & 3.198 & 0.043 & 0.04 \\
\hline $5-2$ & Rigorous peer review & $3.28^{2}$ & 0.81 & 3.73 & 0.71 & 3.83 & 0.75 & 8.288 & $<0.001$ & 0.09 \\
\hline $5-3$ & $\begin{array}{c}\text { Rapid publication of my } \\
\text { paper }\end{array}$ & 3.89 & 0.77 & $3.62^{3}$ & 0.85 & 4.03 & 0.74 & 3.749 & 0.026 & 0.05 \\
\hline $5-8$ & Provision of altmetrics & $3.43^{4}$ & 0.87 & $3.06^{4}$ & 0.70 & 3.49 & 0.75 & 4.579 & 0.012 & 0.06 \\
\hline
\end{tabular}

${ }^{1}$ significant difference between: $0-9$ years and $15+$ years

${ }^{2}$ significant difference between: 0-9 years and $10-14$ years; $0-9$ years and $15+$ years

${ }^{3}$ significant difference between: $10-14$ years and $15+$ years

${ }^{4}$ significant difference between: $0-9$ years and $10-14$ years; $10-14$ years and $15+$ years 